\title{
Skill asymmetries, increasing wage inequality and unemployment*
}

\author{
Peter Skott ${ }^{\dagger} \quad$ Paul Auerbach ${ }^{\ddagger}$
}

October 2, 2000

\begin{abstract}
Using a simple model with two levels of skill, we assume that high-skill workers who fail to get high-skill jobs may accept low-skill positions; low-skill workers do not have the analogous option of filling high-skill positions. This asymmetry implies that a slowdown in Hicks-neutral technical change (or other adverse, skillneutral shocks) may cause an increase in wage inequality, both between and within skill categories, as well as an increase in unemployment, especially among low-skill workers. Movements in productivity, unemployment and inequality may thus be linked to induced overeducation and credentialism.
\end{abstract}

JEL Classification: J31, E24, E25, O33

Keywords: wage inequality, unemployment, skill-bias, Hicks-neutral technical change, overeducation, credentialism.

*We thank Francis Green, Sean Hove and Lars Muus for helpful comments and suggestions.

${ }^{\dagger}$ Department of Economics, University of Aarhus, Building 350, DK 8000 Aarhus C, Denmark. E-mail: pskott@econ.au.dk.

\#Department of Economics, Kingston University, Penrhyn Road, Kingston Upon Thames, Surrey KT1 2EE, England. E-mail: EN_S114@kingston.ac.uk 


\section{Introduction}

This paper focuses on interactions between productivity growth, unemployment and wage inequality. The main facts are well known. In the 1970s and 1980s unemployment rose in all the OECD countries; in Europe it has remained high throughout the 1990s. Productivity growth also slowed down from the early 1970s, with most OECD countries seeing reductions in the growth rates of labour productivity of about 1-4 percentage points. Inequality has been increasing as well, although here the picture is somewhat more complicated. Changes in the wage structure and in personal income distribution have been particularly striking in the US and UK, while so far some continental European countries have avoided significant increases in wage inequality. More recently, productivity growth appears to have picked up again in the US; unemployment rates have returned to the levels of the 1960s and there are signs that these developments have been accompanied by stable or declining wage inequality from the mid 1990s. Some European countries, including the UK, Netherlands, Denmark and Ireland, have also experienced substantial reductions in unemployment in the 1990s.

It is our purpose to present and analyse a mechanism which may have contributed to these trends. The central element of the mechanism was described almost half a century ago by Reder (1955): "When applicants become scarce, employers tend to lower the minimum standards upon which they insist as a condition for hiring a worker to fill a particular job - and vice versa when applicants become plentiful" (p. 834); hence "in periods of general labor shortage, the skill margin would tend to decline" (p. 840-1). ${ }^{2}$

Our argument presumes an asymmetry between high and low skill. A high-skilled worker who fails to get a high-skill job may accept a low-skill position; a low-skill worker, on the other hand, does not have the analogous option of filling a high-skill position. Thus, in line with models of "job competition" (Thurow (1975)), a distinction is made between the skill requirement of a job and the skill of the worker. The asymmetry be-

\footnotetext{
${ }^{1}$ We are grateful to Sean Hove for this reference.

${ }^{2}$ More recently, in a similar vein, Blank (2000, p. 7) has argued that

"Low unemployment has always disproportionately benefited less skilled workers. When employment grows, then the previously unemployed, the part-time workers, the underemployed, and those out of the labor market are most able to benefit. A tight labor market also forces employers to turn to less traditional sources of labor, providing training and job opportunities to workers who might not have been considered for more skilled positions in a different economy."
} 
tween the options facing the two kinds of workers implies that the rate of unemployment among low-skill workers will be more sensitive to changes in aggregate activity than will unemployment among high-skill workers, some of whom will take low-skilled jobs rather than become unemployed. Since increasing numbers of high-skill workers will move into low-skill jobs when times are bad, the dispersion in their incomes will increase, that is, within-group inequality will increase. More importantly, a high average rate of unemployment will cause unemployment among low-skill workers to be particularly high and put pressure on wage rates for low-skill jobs, thus tending to increase the skill premium in high-skill jobs.

The distinction between the skill requirement of a job and the skills of the worker filling the job has been discussed in the empirical literature in terms of "overeducation" and "credentialism". A worker is overeducated if his education exceeds the requirements set by the employer. Credentialism, on the other hand, arises when a change in the pool of applicants leads employers to raise the skills required for recruitment to an otherwise unchanged job. Using this terminology, our argument focuses on endogenous changes in overeducation and credentialism. An adverse, skill-neutral shock to aggregate activity may reduce employment of both high- and low-skill workers, but induced changes in overeducation and credentialism imply that low-skill workers will be hit harder than high-skill workers. ${ }^{3}$

This part of our argument, the effects of neutral shocks to activity on relative employment and on the wage structure, is independent of the origins of these shocks. The productivity slowdown from the early 1970s is one possible shock. We shall argue that a slowdown in technical change, even of the Hicks-neutral type, is capable of causing, and indeed may have caused, an increase in both unemployment and wage inequality. The existence of a link between the fall in productivity growth and increased unemployment has been suggested by a number of studies (e.g. Stiglitz (1997), Blanchard (1998)). Workers, having become accustomed to high annual rates of wage increase, demanded a continuation of this trend. With a decline in productivity growth, this continuation became impossible and unemployment, which dampens wage demands, or inflation was

\footnotetext{
${ }^{3}$ Theoretical models which include the possibility of overeducation have been presented by McKenna (1996), Muysken and Weel (2000) and Deding (2000). These papers use a matching model and focus primarily on the incidence of unemployment in a steady state with endogenous human capital formation. Van Ours and Ridder (1995) also formalise the process of job competition as a matching model; they test the model on Dutch data for 1981-88 and find evidence for job competition at higher but not at lower levels of education; Groot and Hoek (2000) discuss some weaknesses of the study by Van Ours and Ridder.
} 
the result. The NAIRU, in other words, increases until wage aspirations have adapted to the decline in productivity growth. We extend this argument, which is usually presented in an aggregate framework, to a model with two types of workers, high-skilled and low-skilled. This extension allows us to consider the effects of a slowdown on the patterns of both employment on wage inequality.

The effects of induced overeducation and credentialism may be complementary to other, existing explanations of increased inequality: shocks in the form of skill-biassed technical progress with information technology and computerization as the source of the skill bias (e.g. Reich (1993), Berman et al (1994), Autor et al (1998), Bresnahan (1999)); the impact of increased trade and competition from NICs and LDCs (e.g. Wood (1994) Leamer (1994) and Feenstra and Hanson (1999)); institutional changes surrounding unionization and minimum wages (e.g. Freeman (1993), DiNardo et al (1996) and Fortin and Lemieux (1997)). In the interest of analytical simplicity - and to highlight the potential contribution of induced overeducation - we shall assume, however, that the economy is closed, that all technical change is Hicks-neutral in its effects on different types of labour, and that the institutional structure of the labour market is unchanging. Thus, we exclude by assumption the factors which are typically held responsible for the rise in inequality.

The measurement of overeducation and credentialism involves many difficulties, both conceptual and empirical. ${ }^{4}$ There is strong evidence, however, that the incidence of overeducation is substantial. An influential study by Sicherman (1991), for instance, reports that 40 percent of US workers are overeducated in the sense that they had more education than required to get their current job; Hersch (1991) finds overeducation figures ranging from 28 to 78 percent for different groups of workers in a sample from Oregon, and Bewley's (1998) study of wage stickiness in the American Northeast during the early 1990s showed that "unemployed overqualified applicants were common in the Northeast during the recession. The label applies to semi-skilled and skilled manual workers as well as to technicians, professionals and managers" (p. 481). In the UK, several studies indicate that about 30 percent of all respondents were overeducated and that the figure may be above 40 percent among those possessing more than the lowest level of qualifications (Sloane et al (1999), Dolton and Vignoles (2000), Rigg et al (1990)). Summarizing the evidence, Green et al (1999, p.15) suggest that "overeducation is a widespread phenomenon both in Europe and the United States of America". Undereducation - workers who report having less education than required to get the job

\footnotetext{
${ }^{4}$ Green et al (1999) and Hartog (2000) discuss some of the issues involved.
} 
- also exists. Quantitatively, most studies indicate that about 10-20 percent of all workers are undereducated. The very existence of undereducation on this scale may indicate credentialism: it would seem to imply that although employers may want workers with the "required education", this level is not needed to do the job.

From the perspective of the present paper, it is not merely the levels, but also the changes in the incidence of overeducation and credentialism that are critical. With induced overeducation, a rise in unemployment tends to increase overeducation. When it comes to short run fluctuations, however, this effect may be offset by the effects of differential labour hoarding. ${ }^{5}$ Like induced overeducation, differential labour hoarding implies that low-skill workers are affected disproportionately by unemployment, but the underlying mechanism and the effects on measured overeducation will be different. Induced overeducation focuses on the effects on different groups of workers of proportional changes in the number of high- and low-skill jobs; differential labour hoarding, on the other hand, suggests that temporary changes in demand will lead to non-proportional changes in the number of jobs, and when high-skill workers in low-skill jobs are laid off as a result of differential labour hoarding, there is a tendency for overeducation to decrease. A priori it is difficult to say which of these effects will dominate in the short run. ${ }^{6}$ In the medium term, however, differential hoarding ceases to be important and we would expect a negative correlation between employment and overeducation.

In the UK, evidence suggests that the incidence of overeducation increased strongly between the 1970s and 1980s (a period of rising unemployment) but may have stabilized since the late 1980s (Green et al (1999)). With respect to credentialism, Rigg et al (1990) present evidence to the effect that in the late 1980s, 25 percent of UK employers had substituted graduates for non-graduates; only about a third of these jobs had been upgraded in terms of content. Furthermore, in the UK an index of required qualifications rose between 1986 and 1992, but then fell slightly during the period of falling unemployment from 1992 to 1997 (Green et al (2000)). More generally, Hartog's (2000) survey of the literature reports an increasing incidence of overeducation (and decreasing

\footnotetext{
${ }^{5}$ It is well-known that because of differential labour hoarding, fluctuations in aggregate activity can lead to fluctuations in relative labour demand and wage inequality (e.g. Murphy and Welch (1992)). Empirical work supports the extension of the adverse effects of unemployment on income distribution to time-scales beyond short-run fluctuations; e.g. Blinder and Esaki (1978) and Jäntti (1994).

${ }^{6}$ There is some evidence that differential labour hoarding may dominate in the short run. Thus, using Dutch data from the 1990s, Gautier (2000) reports that the proportion of high-skill workers in low-skill positions falls in a recession. The measure of overeducation will be biassed, however, insofar as some workers in high-skill jobs temporarily take over low-skill tasks (Doeringer and Piore (1971)).
} 
undereducation) since the 1970 s in a number of countries. ${ }^{7}$ In the US, the evidence is ambiguous. Doeringer and Piore (1971) report the widespread use of "bumping": large American firms with well-developed internal labor markets, they argue, respond to a temporary decline in demand by laying off unskilled workers and letting their skilled workers take over unskilled jobs. In a longer-term perspective, Wolff (2000, p. 27) concludes that between 1950 and 1990 there has been a growing mismatch "between skill requirements of the workplace and the educational attainment of the workforce, with the latter increasing much more rapidly than the former". Daly et al. (2000), on the other hand, find a decline in overeducation between 1976 and 1985. With a rapid rise in average years of schooling, however, overeducation may increasingly take the form of a discrepancy between actual and required quality of education; a focus on years of schooling will fail to register any overeducation if, for instance, MIT graduates accept jobs which otherwise could and would have been filled by graduates from local colleges. ${ }^{8}$

The remainder of this paper is in 4 sections. Section 2 sets out a standard model in which biassed technical progress is needed in order to generate increases in both the relative wage and the relative employment of skilled workers. Section 3 examines the implications of introducing the asymmetry between the job options of skilled and unskilled workers. With the assumption that any technical change is purely Hicks-neutral, we derive the implications of changes in the employment pattern for wage inequality, both between and within skill categories. Secondly, we show that for plausible parameter values, the predictions of the model are broadly consistent with the empirical evidence for both US and Germany. Section 4 endogenizes the changes in employment. It is shown that a decline in Hicks-neutral technical change may produce an increase in the relative employment of skilled workers, in combination with increased wage disparities. Using the chosen specification of the supply side of the labour market, the model can match

\footnotetext{
${ }^{7}$ In their meta-analysis of 25 studies of overeducation, Groot and Maassen van den Brink (2000, p. 153) suggest that the "incidence of overeducation appears to have declined". This conclusion, based on raw averages, is contradicted by their own regression results, which control for some of the differences across studies with respect to, inter alia, the definition of overeducation (Table 3). Groot and Maassen van den Brink also suggest (Table 4) that the incidence of overeducation is unrelated to unemployment. A simple cross-section analysis of the results obtained in studies from a number of different countries says little, however, about the time-series effects of changes in unemployment.

${ }^{8}$ Dolton and Vignoles (2000) point out this problem and report that, in the UK, "graduates with a higher quality education, i.e. those who attended universities (rather than polytechnics - see Appendix B) and those having better degree grades were less likely to be overeducated" when overeducation is defined as a graduate working in a job that does not require a graduate degree (Dolton and Vignoles (2000, p. 183)).
} 
the observed changes in the patterns of employment and inequality in US, but not in Germany. Section 5 contains a few concluding remarks. All proofs have been collected in Appendices.

\section{A standard view}

For simplicity, assume that there are only two kinds of workers, high-skilled and lowskilled, and that the supplies of these two types of labour are kept constant at $H$ and $L$, respectively. Furthermore, let the production function of the representative firm exhibit constant returns to scale with respect to these two labour inputs ${ }^{9}$,

$$
Y=A F\left(N_{H}, N_{L}\right)
$$

where $Y$ is output; $N_{H}$ and $N_{L}$ denote input of high- and low-skilled labour, respectively, and where changes in the multiplicative constant $A$ describe Hicks-neutral technical change. If firms face given wage rates, the first order conditions for profit maximization imply that

$$
\begin{aligned}
\frac{W_{H}}{P} & =m A F_{1}=m A f^{H}\left(\frac{N_{H}}{N_{L}}\right) ; f^{H \prime}<0 \\
\frac{W_{L}}{P} & =m A F_{2}=m A f^{L}\left(\frac{N_{H}}{N_{L}}\right) ; f^{L \prime}>0
\end{aligned}
$$

where $F_{1}$ and $F_{2}$ are the partial derivatives of $F$. The proportionality factor $m$ is given by $m=1+\frac{d \log P}{d \log Y} \leq 1$ which reduces to $m=1$ in the simple case with perfectly competitive product markets. Using (2) and (3), the relative wage can be written

$$
\frac{W_{H}}{W_{L}}=\frac{f^{H}}{f^{L}}=h\left(\frac{N_{H}}{N_{L}}\right) ; h^{\prime}<0
$$

\footnotetext{
${ }^{9}$ The assumptions of linear homogeneity and the absence of other inputs can be relaxed. Consider a general specification

$$
Y=A \psi\left(N_{H}, N_{L}, Z\right)
$$

where $Z$ is a vector of other inputs. The analysis would go through substantially unchanged on the weaker assumptions that

(i) $\psi$ is separable in $\left(N_{H}, N_{L}\right)$ and $Z$ so that the production function can be rewritten

$$
Y=A \varphi\left(\theta\left(N_{H}, N_{L}\right), Z\right)
$$

and

(ii) the function $\theta$, which aggregates the two types of labour input, is homothetic.
} 
Equations (1) to (4) describe the demand for labour and, in the terminology of Carlin and Soskice (1990), equations (2)-(3) give the "price-determined real wages" for the two groups of workers. Since the total supplies of high- and low-skilled labour are assumed constant, a standard specification of the "bargained real wage" implies that ${ }^{10}$

$$
\begin{aligned}
\frac{W_{H}}{P} & =B g^{H}\left(N_{H}\right) ; g^{H \prime}>0 \\
\frac{W_{L}}{P} & =B g^{L}\left(N_{L}\right) ; g^{L \prime}>0
\end{aligned}
$$

Some implications of this standard model are summarized in Proposition 1.

Proposition 1 Equations (1)-(6) determine a unique equilibrium solution. This equilibrium solution, $\left(N_{H}^{*}, N_{L}^{*},\left(W_{H} / P\right)^{*},\left(W_{L} / P\right)^{*}\right)$, has the following properties:

(i) an adverse, Hicks-neutral productivity shock (a decrease in A) or an increase in the monopoly markup (a decrease in $m$ ) leads to a decline in all four variables.

(ii) an upward shift in the bargained real wage curve (an increase in B) also causes $N_{H}^{*}$ and $N_{L}^{*}$ to drop but in this case $\left(W_{H} / P\right)^{*}$ and $\left(W_{L} / P\right)^{*}$ must either remain unchanged or change in opposite directions.

(iii) changes in $A, m$ or $B$ will cause relative employment $\left(N_{H}^{*} / N_{L}^{*}\right)$ and relative wage rates $\left(W_{H}^{*} / W_{L}^{*}\right)$ to change in opposite directions. This result is independent of the specification of the equations for the bargained real wage.

It follows from Proposition 1 (iii) that in this standard set-up one needs to introduce skill-biassed technical change (that is, shifts in the $h$-function in (4)) in order to obtain a pattern that fits the stylized facts of a rise in both $W_{H} / W_{L}$ and $N_{H} / N_{L}$.

\section{The skill asymmetry}

The asymmetry between the options of high- and low-skilled workers can be captured by a reformulation of the model. As before, let the constant supplies of high- and lowskilled workers be $H$ and $L$, and assume that production requires the performance of both skilled and unskilled tasks. High-skilled workers, however, may now be employed in either skilled or unskilled jobs. Algebraically,

$$
H=N_{H}+N_{L H}+U_{H}=N_{H T}+U_{H}
$$

\footnotetext{
${ }^{10}$ In order to ensure that $N_{H} \leq H$ and that $N_{L} \leq L$ it is assumed that $g^{H} \rightarrow \infty$ for $N_{H} \rightarrow H$ and that $g^{L} \rightarrow \infty$ for $N_{L} \rightarrow L$.
} 


$$
\begin{gathered}
L=N_{L L}+U_{L} \\
N_{L}=N_{L L}+N_{L H}
\end{gathered}
$$

where $N_{H}$ and $N_{L H}$ are the employment of high-skill workers in skilled and unskilled jobs, respectively, and $N_{H T}=N_{H}+N_{L H}$ is total employment of high-skill workers; $N_{L L}$ is the employment of unskilled workers in unskilled jobs, and $U_{H}$ and $U_{L}$ denote unemployment of skilled and unskilled workers. With these definitions, the specification of the production function, equation (1), remains valid.

The composition of unskilled employment could be determined in a number of ways and we shall use a particularly simple formulation:

$$
N_{L H}=\lambda\left(H-N_{H}\right) ; 0 \leq \lambda \leq 1
$$

Equation (10) says that a constant fraction $\lambda$ of those skilled workers who fail to get a skilled job will find and accept unskilled employment. ${ }^{11}$ This specification makes it straightforward to consider the implications of different values of $\lambda$ between zero and one. It would be useful, however, to have some idea of the relevant range of $\lambda$-values.

One approach to this question is to note that the total supply of labour for unskilled jobs can be found as the sum of the unskilled labour force and those skilled workers who fail to get skilled jobs. From this total pool, the proportion $\mu=N_{L} /\left(L+H-N_{H}\right)$ find unskilled work. If the employment probability of high-skill workers is at least as high as that of low-skill workers, we would then have $N_{L L} \leq \mu L$ and $N_{L H}=\lambda\left(H-N_{H}\right) \geq$ $\mu\left(H-N_{H}\right)$. It follows that the employment rate for low-skilled workers gives a lower

\footnotetext{
${ }^{11}$ As long as skilled work is preferred to unskilled, $N_{L H}$ should depend inversely on $N_{H}$. But for those skilled workers who fail to get skilled jobs, the attractiveness of unskilled work will depend inversely on the relative wage $W_{H} / W_{L}$ while, for a given $N_{H}$, the ease of getting unskilled work will be positively related to $N_{L} / N_{H}$. These considerations suggest a more general specification

$$
N_{L H}=\phi\left(N_{H}, \frac{N_{L}}{N_{H}}, \frac{W_{H}}{W_{L}}\right) ; \phi_{1}<0, \phi_{2}>0, \phi_{3}<0
$$

or, substituting from (4),

$$
N_{L H}=\phi\left(N_{H}, \frac{N_{L}}{N_{H}}, h\left(\frac{N_{H}}{N_{L}}\right)\right)
$$

The net effect of $N_{L} / N_{H}$ on $N_{L H}$ is ambiguous, however, and the benchmark specification in (10) assumes that the effects of $N_{L} / N_{H}$ and $h\left(N_{H} / N_{L}\right)$ cancel out and that $N_{L H}$ is fully determined by $N_{H}$ :

$$
N_{L H}=\phi\left(N_{H}\right) ; \phi(H)=0,-1<\phi^{\prime}<0
$$
}

With a linear specification of $\phi\left(N_{H}\right)$, equation (10) is now obtained. 
bound on $\lambda$ and, using plausible unemployment and participation rates, implies $\lambda$-values of at least 0.6.

The empirical evidence on the incidence of overeducation can be used to derive an alternative estimate of the order of magnitude of $\lambda$. Thus, if it is assumed - in line with the evidence - that at least 30 percent of all workers are overeducated and if $H=L$ then the linear specification in (10) implies a $\lambda$-value of over 0.8 for plausible values of the employment rates. ${ }^{12}$ Thus, the different approaches suggest $\lambda$-values somewhere in the range from 0.5 to one.

Equations (2)-(4), which are derived from firms' maximization problem, still hold if $W_{H}$ denotes the wage rate paid for skilled work, as opposed to the average wage received by skilled workers; the latter now is given by

$$
W_{H A}=\frac{W_{H} N_{H}+W_{L} N_{L H}}{N_{H T}}
$$

Wage inequality in this set-up takes two forms. Inequality between skill categories is captured by the ratio $W_{H A} / W_{L}$ while the dispersion of wages among high-skill workers can be described by

$$
\sigma=\sqrt{\frac{N_{H}}{N_{H T}}\left(\frac{W_{H}-W_{H A}}{W_{H A}}\right)^{2}+\frac{N_{L H}}{N_{H T}}\left(\frac{W_{L}-W_{H A}}{W_{H A}}\right)^{2}}
$$

The wage equations (5)-(6), finally, will need to be modified. We shall return to this issue in section 4 but for the moment take changes in observed employment rates for high and low-skill workers as exogenously given. The implications of such changes in $N_{H T}$ and $N_{L L}$ for $N_{H}, N_{L}, W_{H A} / W_{L}$ and $\sigma$ are summarized in Proposition 2.

Proposition 2 Equations (2)-(3), and (7)-(12) imply that

$$
\begin{gathered}
N_{H}=\frac{N_{H T}-\lambda H}{1-\lambda} \\
N_{L}=N_{L L}+\frac{\lambda}{1-\lambda}\left(H-N_{H T}\right)
\end{gathered}
$$

\footnotetext{
${ }^{12}$ Using (10), the condition

$$
\frac{N_{L H}}{N_{H T}+N_{L L}} \geq 0.3
$$

can be rewritten

$$
\frac{\lambda}{1-\lambda} \geq 0.3\left(\frac{N_{H T}+N_{L L}}{H-N_{H T}}\right)
$$

With $H=L$ the second term on the right hand side is unlikely to be less than 15 . It follows that $\lambda$ will exceed $4.5 / 5.5 \approx 0.82$.
} 
and we have the following expressions for $d \log N_{H}, d \log N_{L}, d \log \frac{W_{H A}}{W_{L}}$ and $d \log \sigma$ :

$$
\begin{gathered}
d \log N_{H}=\frac{N_{H T}}{N_{H T}-\lambda H} d \log N_{H T} \\
d \log N_{L}=\frac{1}{N_{L L}+\frac{\lambda}{1-\lambda}\left(H-N_{H T}\right)}\left[N_{L L} d \log N_{L L}-\frac{\lambda}{1-\lambda} N_{H T} d \log N_{H T}\right] \\
d \log \frac{W_{H A}}{W_{L}}=\frac{\frac{W_{H}}{W_{L}} N_{H}}{\frac{W_{H}-W_{L}}{W_{L}} N_{H}+N_{H T}}\left[\eta d \log N_{L}+\left(-\eta+\frac{W_{H}-W_{L}}{W_{H}} \frac{\lambda H}{N_{H T}}\right) d \log N_{H}\right] \\
d \log \sigma=\frac{W_{L}}{W_{H A}-W_{L}} d \log \frac{W_{H A}}{W_{L}}-\frac{1}{2} \frac{H}{H-N_{H}} d \log N_{H}
\end{gathered}
$$

where

$$
\eta=-\frac{d \log \frac{W_{H}}{W_{L}}}{d \log \frac{N_{H}}{N_{L}}}=-\frac{d \log h\left(\frac{N_{H}}{N_{L}}\right)}{d \log \frac{N_{H}}{N_{L}}}>0
$$

is the inverse of the elasticity of substitution.

With the introduction of a skill asymmetry and the assumption that some high-skill workers have low-skill jobs, the ratios $N_{H} / N_{L}$ and $N_{H T} / N_{L L}$ may move in opposite directions and a skill bias may no longer be needed to explain the simultaneous increase in relative employment and relative wages. The somewhat complicated expression for $d \log W_{H A} / W_{L}$ in Proposition 2 reflects this basic result. But is this logical possibility likely to be empirically relevant?

Movements in the same direction for relative employment and relative wages have been seen as evidence of increasing skill bias. In the past, supposedly, the trend increase in the demand for skills was matched by a trend increase in supply; in the more recent period, it is claimed that the demand for skills has outgrown supply as a result of an increase in skill bias. Common trends in the demand and supply for skills are not relevant to the present argument. To simplify the exposition we have therefore assumed a constant skill composition of the work force (that is, constant values of $H$ and $L$, thus removing the trend increase in the supply of skills) and have taken Hicks-neutral technical change as the standard pattern (thus removing the trend increase in the demand for skills).

If we look at the figures for men and take low skill to mean "lower secondary education or less" and high-skill as "college level or higher", the ratios $\frac{N_{H T}}{H} / \frac{N_{L L}}{L}$ and $W_{H A} / W_{L}$ increased by about 17 and 21 percent, respectively, in the US between 1970 and 1990 (OECD 1994, Tables 1.6, 1.10 and 1.16). The change in the ratio $\frac{N_{H T}}{H} / \frac{N_{L L}}{L}$ can be broken 
into a 3 percent decline in $\frac{N_{H T}}{H}$ combined with a 20 percent decline in $\frac{N_{L L}}{L}$. Furthermore, the initial values of the employment rates were $\frac{N_{H T}}{H}=0.94$ and $\frac{N_{L L}}{L}=0.85$, the supplies of high and low skill were roughly equal, and the initial value of $W_{H} / W_{L}$ was about 2 (OECD 1994, Tables 1.6 and 1.16, Chart 5.2). Using equations (15)-(16) these numbers imply that

$$
\begin{aligned}
& d \log N_{H}=-\frac{0.94}{0.94-\lambda} 0.03 \\
& d \log N_{L}=d \log \left(N_{L L}+N_{L H}\right)=\frac{0.85}{0.85+\frac{\lambda}{1-\lambda} 0.06}\left(-0.20+\frac{\lambda}{1-\lambda} \frac{0.94}{0.85} 0.03\right)
\end{aligned}
$$

and we get the following table, which lists the changes in $N_{H}$ and $N_{L}$ for different values of $\lambda$.

Table 1: Changes in $d \log N_{H}$ and $d \log N_{L}$

using stylized US data and different values of $\lambda$

$$
\begin{array}{cccccc}
d \log N \backslash \lambda & 0.5 & 0.6 & 0.7 & 0.8 & 0.9 \\
d \log N_{H} & -0.064 & -0.083 & -0.118 & -0.201 & -0.705 \\
d \log N_{L} & -0.156 & -0.136 & -0.105 & -0.052 & 0.060
\end{array}
$$

As indicated by Table $1, \lambda$-values above 0.7 imply that $N_{H} / N_{L}$ will decline despite the observed increase in $\frac{N_{H T}}{H} / \frac{N_{L L}}{L}$. It is the ratio $N_{H} / N_{L}$ which - via equation (4) - determines the change in $W_{H} / W_{L}$, but since some skilled workers have moved into unskilled jobs, an increase in $W_{H} / W_{L}$ does not necessarily imply that the average wage of skilled workers will have gone up relative to the unskilled wage.

Turning to the measures of wage inequality, equations (17)-(18), in combination with the results in Table 1, allow us to calculate the predicted changes in $W_{H A} / W_{L}$ and $\sigma$ for different values of $\lambda$ and $\eta$. As argued above, we expect $\lambda$ to lie between 0.5 and one. Furthermore, one would expect a relatively high value for the flexible US labour market and relatively low values for European labour markets, which are supposedly characterized by sharper and more rigid demarcations of skill boundaries. The elasticity of substitution between low- and high-skill tasks is likely to be below unity, and we consider values of $\eta$ - the inverse of the elasticity of substitution - from 1 to $4 .{ }^{13}$

\footnotetext{
${ }^{13}$ All estimates of the elasticity of substitution between different skill categories in Card et al (1999) are very low (and in some cases negative). Murphy and Welch (1992) present estimates of the elasticities of complementarity (which are closely related to $\eta_{H}$ and $\eta_{L}$ ) which suggest $\eta$-values in the 1-3 range between high school and college graduates. Katz and Murphy (1992), on the other hand, estimate an
} 
Table 2: $d \log \frac{W_{H A}}{W_{L}}$ and $d \log \sigma$ using stylized US data and different values of $\lambda$ and $\eta$

\begin{tabular}{cccccccccc}
\multicolumn{1}{c}{$d \log \frac{W_{H A}}{W_{L}}$} & \multicolumn{1}{c}{$d \log \sigma$} \\
$\lambda \backslash \eta$ & 1 & 2 & 3 & 4 & $\lambda \backslash \eta$ & 1 & 2 & 3 & 4 \\
0.5 & -0.105 & -0.194 & -0.283 & -0.371 & 0.5 & 0.154 & 0.060 & -0.035 & -0.130 \\
0.6 & -0.075 & -0.126 & -0.176 & -0.226 & 0.6 & 0.193 & 0.138 & 0.082 & 0.026 \\
0.7 & -0.029 & -0.018 & -0.006 & 0.005 & 0.7 & 0.260 & 0.273 & 0.286 & 0.299 \\
0.8 & 0.054 & 0.181 & 0.308 & 0.435 & 0.8 & 0.408 & 0.579 & 0.750 & 0.920 \\
0.9 & 0.255 & 0.712 & 1.169 & 1.626 & 0.9 & 1.188 & 2.261 & 3.335 & 4.409
\end{tabular}

Table 2 shows that for $\lambda=0.8$ the observed change of about 20 percent in the wage ratio $W_{H A} / W_{L}$ can be fully accounted for by the observed changes in employment if $\eta$ is just above 2. The predicted proportional change in the wage dispersion for skilled workers then becomes about 60 percent. This figure may seem high but in fact it fits the observed increase in the "within education and experience" dispersion of wages quite well (Welch 1999). Thus, with these parameter values, there would be no need to invoke skill-biases or other explanations. Lower values of $\lambda$ and $\eta$ reduce the fraction of the observed change that is accounted for.

It may be interesting to do the analogous calculations for Germany. The German economy is commonly believed to have a rigid labour market - which would suggest a lower value of the parameter $\lambda$ than in the $\mathrm{US}^{14}$ - and the changes in wage inequality also differ significantly from those in the US. Between 1978 and 1987 the $\frac{N_{H T}}{H} / \frac{N_{L L}}{L}$ increased by about 10 percent but - in contrast to the US - skilled workers did not increase their relative wages: the wage ratio $W_{H A} / W_{L}$ declined by 3 percent (OECD 1994, Tables 1.6, $1.10,1.16) .{ }^{15}$

Using German stylized facts, ${ }^{16}$ we get the results in Table 3.

elasticity of substitution of 1.4 but themselves express skepticism since the estimate is "recovered from 25 non-independent time series observations". Since these estimates are based on the assumption that $N_{H T}=N_{H}$ and $N_{L L}=N_{L}$, they all may be biased if there is significant overeducation, as modelled in this paper.

${ }^{14}$ Consistent with this expectation, Daly et al. (2000, p. 172) report that "German men are about half as likely to be overeducated and about $60 \%$ less likely to be undereducated than working men in the United States. The same pattern holds for German women."

${ }^{15}$ The figures on wage movements are subject to considerable uncertainty. Some sources suggest a small increase in wage inequality (e.g Nickell and Bell (1996)).

${ }^{16}$ We use $N_{H T} / H=0.96, N_{L L} / L=0.91$ and $W_{H} / W_{L}=2$ as the initial values and assume $H=L$. 
Table 3: $d \log \frac{W_{H A}}{W_{L}}$ and $d \log \sigma$ using stylized German data and different values of $\lambda$ and $\eta$

\begin{tabular}{cccccccccc}
\multicolumn{1}{c}{$d \log \frac{W_{H A}}{W_{L}}$} & \multicolumn{1}{c}{$d \log \sigma$} \\
$\lambda \backslash \eta$ & 1 & 2 & 3 & 4 & $\lambda \backslash \eta$ & 1 & 2 & 3 & 4 \\
0.5 & -0.038 & -0.059 & -0.080 & -0.102 & 0.5 & 0.352 & 0.330 & 0.307 & 0.285 \\
0.6 & -0.013 & -0.001 & 0.011 & 0.022 & 0.6 & 0.387 & 0.399 & 0.411 & 0.424 \\
0.7 & 0.027 & 0.092 & 0.158 & 0.223 & 0.7 & 0.445 & 0.518 & 0.590 & 0.663 \\
0.8 & 0.101 & 0.269 & 0.438 & 0.607 & 0.8 & 0.571 & 0.774 & 0.976 & 1.178 \\
0.9 & 0.287 & 0.747 & 1.207 & 1.667 & 0.9 & 1.059 & 1.795 & 2.531 & 3.268
\end{tabular}

Thus, with an $\eta$-value of 2 , a perfect fit with the observed change of about -0.03 is obtained for a $\lambda$-value between 0.5 and 0.6. The proportional change in the dispersion of wages for high-skill workers in this case is about 35 percent.

Although far from conclusive, these calculations indicate that the effects of skill asymmetries and induced changes in overeducation can be quantitatively important: the observed changes in relative wages and employment could be explained without recourse to biassed technical progress, using what appear to be plausible parameter values.

\section{Endogenizing changes in employment}

Our exposition of the standard view in section 2 derived equilibrium values for wages and employment. In section 3, by contrast, we retained the specification of the demand side of the labour market (that is, equations (1)-(4) still hold) but took the changes in

Skilled employment $N_{H T} / H$ fell by 3 precent while unskilled employment $N_{L L} / L$ dropped by 12 percent.

Note that the relative employment performance for low skill workers in the US is worse than in Germany. The US does better if one looks at unemployment rates: US unemployment among low-skill male workers increased from 4.0 percent to 9.7 percent between 1970 and 1989 while the German rate increased from 4.1 percent to 14.6 percent between 1978 and 1987. Participation rates moved very differently, however. In the US it plummeted from 89.3 percent to 75.9 percent while the German participation rate remained almost constant showing a small decline from 93.6 percent in 1978 to 91.6 percent in 1987. These figures for Germany and the US should be comparable in the sense that the proportions of the labour force in the low- and high-skill categories were roughly the same for the two countries. For the low-skill category the numbers were about 20 and 23 percent, respectively, in 1978/79; the corresponding high-skill numbers were about 10 and 24 percent. (In comparison, about 79 percent of the UK labour force was in the low skill category according to the OECD.) 
the employment of high and low-skilled workers, $N_{H T}$ and $N_{L L}$ as exogenous. We now endogenize these changes by incorporating the supply side of the labour market.

The skill asymmetry implies that equations (5)-(6) will have to be modified. Equation (5), first, should allow for the fact that downward pressure on the skilled wage will come from two sources: unemployed high-skill workers and high-skill workers in unskilled jobs. Depending on the unskilled wage, however, unskilled employment is likely to be preferable to unemployment. Thus, for any given level of skilled employment, the skilled wage may depend positively on the employment of skilled workers in unskilled positions. Algebraically, ${ }^{17}$

$$
\frac{W_{H}}{P}=B g^{H}\left(\frac{N_{H}}{H}, \frac{N_{L H}}{H}, \frac{W_{L}}{P}\right) ; g_{1}^{H} \geq g_{2}^{H} \geq 0, g_{3}^{H} \geq 0
$$

This type of equation could be derived using a variety of models for the labour market. A simple argument based on efficiency wage considerations runs as follows.

Assume that there are two possible effort levels, 0 and 1, and that a high-skill worker with a skilled job in firm $i$ chooses $e=1$ if and only if the real wage in firm $i\left(\frac{W_{H, i}}{P}\right)$ exceeds the worker's expected income in case of dismissal by a factor $\gamma>1$,

$$
\frac{W_{H, i}}{P} \geq \gamma G\left(\frac{N_{H}}{H}, \frac{N_{L H}}{H}, \frac{W_{H}}{P}, \frac{W_{L}}{P}, b_{u}\right) ; G_{1}>0, G_{2}>0, G_{3}>0, G_{4}>0, G_{5}>0
$$

where the expected income in case of dismissal - represented by the $G$-function - is determined by the level of unemployment benefits $\left(b_{u}\right)$, the wage rates in other highand low-skill jobs $\left(\frac{W_{H}}{P}, \frac{W_{L}}{P}\right)$ and the perceived probabilities of getting another, highor low-skill job as determined by the current employment rates $\left(\frac{N_{H}}{H}, \frac{N_{L H}}{H}\right)$. A profit maximizing firm will set its wage such that (23) is satisfied with equality, and in a symmetric equilibrium with all firms acting alike we have $\frac{W_{H, i}}{P}=\frac{W_{H}}{P}$. Suppressing unemployment benefits - which are assumed constant - we get an expression like (22) for the real wage.

Turning now to the determination of $W_{L} / P$, equation (6) is replaced by

$$
\frac{W_{L}}{P}=B g^{L}\left(\frac{N_{L L}}{L}\right) ; g^{L \prime}>0
$$

Equation (24) can be given an efficiency wage interpretation along the same lines as (22) above: low-skill workers shirk unless their real wage exceeds their expected income in

\footnotetext{
${ }^{17}$ As in the previous section, conditions must be imposed in order to ensure that $N_{H} \leq H$ and that $N_{L} \leq L$. Here the conditions take the form: $g^{H}\left(N_{H}, 0,0\right) \rightarrow \infty$ for $N_{H} \rightarrow H$ and $g^{L}\left(N_{L L}\right) \rightarrow \infty$ for $N_{L L} \rightarrow L$.
} 
case of dismissal by a certain margin. The expression is simpler than in (22), since the expected income of a low-skill worker does not depend on wages and employment rates in high-skill jobs.

This efficiency wage argument rationalizes (24) with respect to the real wage paid to low-skill workers in unskilled jobs. By assumption, however, some high-skill workers have unskilled jobs. The expected income of these high-skill workers in case of dismissal is higher than that of low-skill workers: unlike low-skill workers, an unemployed highskill worker has a chance of getting a well-paid high-skill job and, secondly, the overall unemployment rate - and thus the probability of remaining unemployed - is likely to be lower for high-skill workers. This lower cost of job loss for high-skill workers in lowskill jobs need not imply that these workers will shirk: a high-skill worker in a low-skill job may also find the effort associated with non-shirking less arduous than a low-skill worker. We shall assume that this effect on the disutility of effort dominates the reduced cost of job loss and that high-skill workers in low-skill jobs will set $e=1$ at the wage rate determined by (24). Any attempt to pay them less than low-skill workers will be considered unfair, however, and provoke shirking. ${ }^{18}$ Thus, (24) must hold for both highand low-skill workers in unskilled jobs. ${ }^{19}$

With these assumptions, we can now prove the following result.

Proposition 3 (i) Equations (2)-(3), (9)-(10), (22) and (24) yield a unique equilibrium solution $\left(N_{H}^{*}, N_{L}^{*}, N_{L L}^{*}, N_{L H}^{*},\left(W_{H} / P\right)^{*},\left(W_{L} / P\right)^{*}\right)$,

(ii) an increase in $A m$ or a decrease in $B$ leads to a rise in $N_{H}^{*}$, the change in $N_{L}^{*}$

${ }^{18}$ Formally, a high-skill worker with a low-skill job in firm $i$ sets $e=1$ if

$$
\frac{W_{L, i}}{P} \geq \max \left\{\gamma^{L} G^{L}\left(\frac{N_{H}}{H}, \frac{N_{L H}}{H}, \frac{W_{H}}{P}, \frac{W_{L}}{P}, b_{u}\right), \frac{W_{L}}{P}\right\}
$$

where first term on the right hand side is analogous to (23) and the second term represents the fairness requirement. It is assumed that $W_{L} / P$ represents the maximum when $W_{L} / P$ is given by $(24), W_{H} / P$ by (22), and $N_{L H}$ by (10).

${ }^{19}$ An alternative, more complicated approach would be to leave out the fairness considerations and to use the equality between the wage rates determined by the no-shirking conditions for high- and low-skill workers to endogenize the employment of high-skill workers in low-skill jobs. Algebraically, let

$$
\frac{W_{L, i}}{P} \geq \gamma^{L} G^{L}\left(\frac{N_{H}}{H}, \frac{N_{L H}}{H}, \frac{W_{H}}{P}, \frac{W_{L}}{P}, b_{u}\right)
$$

be the no-shirking condition for high-skill workers in low-skill jobs, and use this condition in combination with (22), (24) and the equilibrium condition $W_{L, i}=W_{L}$ to determine $N_{L H}, W_{H} / P$ and $W_{L} / P$ as functions of $N_{H} / H$ and $N_{L L} / L$ (and the exogenous variable $b_{u}$ ). This equilibrium determination of $N_{L H}$ would replace the simple linear specification in (10). 
is ambiguous, and the relative wage $W_{H}^{*} / W_{L}^{*}$ and employment ratio $N_{H}^{*} / N_{L}^{*}$ move in opposite directions, and

(iii) an increase in Am or a decrease in $B$ leads to a rise in $N_{H}^{*} / N_{L}^{*}$ and a decline in $W_{H}^{*} / W_{L}^{*}$ if the wage equations (22) and (24) are symmetric in the sense that, taking into account the determination of $N_{L H}$ by (10), the same proportional increase in $N_{H T}$ and $N_{L L}$ leaves the ratio of the bargained real wages, $W_{H} / W_{L}$, unaffected.

The intuition behind the ambiguity of the change in $N_{L}$ (Proposition 3 (ii)) and the rise in $N_{H} / N_{L}$ (Proposition 3 (iii)) is straightforward. A rise in productivity, for instance, causes $N_{H}$ to increase and therefore fewer skilled workers accept unskilled jobs. Thus, even if $N_{L}$ is unchanged, the composition of workers in unskilled jobs will have changed: $N_{L L}$ will have risen and this compositional change - this increase in the employment rate for unskilled workers - puts upwards pressure on the unskilled wage. If the compositional effect on wage pressure is sufficiently strong, the wage demand $W_{L} / P$ at the existing level of $N_{L}$ may exceed the value of the marginal product of unskilled work despite the rise in productivity and the equilibrium solution will involve a decline in $N_{L}$.

Proposition 3 says that neutral changes in technology, in the degree of monopoly or in worker militancy will affect relative wages and hence also relative employment rates. Thus, in the symmetric case described by Proposition 3 (iii), a fall in $A$, for instance, will lead to an increase in $W_{H} / W_{L}$ and a decrease in $N_{H} / N_{L}$. The ratios $W_{H} / W_{L}$ and $N_{H} / N_{L}$ do not, however, capture the relative fortunes of skilled and unskilled workers. For that, one needs to look at the ratios $W_{H A} / W_{L}$ and $N_{H T} / N_{L L}$, but Proposition 3 is consistent with an outcome in which a decline in $A m / B$ causes both of these ratios to rise.

This possibility is most readily demonstrated in the special case in which the wage equations $(22)$ and (24) take the following form ${ }^{20}$

$$
\begin{aligned}
\frac{W_{H}}{P} & =B N_{H T}^{\mu} \\
\frac{W_{L}}{P} & =B N_{L L}^{\mu}
\end{aligned}
$$

Even with this simple specification, the model will not be log-linear when $\lambda$ is positive and an explicit solution is hard to obtain. Comparative effects of changes in $A m$ and $B$

\footnotetext{
${ }^{20}$ This specification is also used by Card et al (1999). Since they do not consider overeducation, however, $N_{H T}=N_{H}$ and $N_{L L}=N_{L}$ in their setup.
} 
can be found, however. Straightforward but cumbersome calculations (see Appendix D) show that:

Proposition 4 Equations (2)-(3), (9)-(10) and (25)-(26) imply that

$$
\begin{gathered}
\frac{d \log \frac{N_{H}}{N_{L}}}{d \log \frac{A m}{B}}=\frac{\lambda H\left(N_{H T}+N_{L L}\right)}{\left(\mu \frac{(1-\lambda) N_{H}}{N_{H T}} N_{L}+\left(\eta-\eta_{L} \frac{\lambda H}{N_{H T}}\right) N_{L L}+\eta_{H} \lambda H\right) N_{H T}}>0 \\
\frac{d \log \frac{W_{H}}{W_{L}}}{d \log \frac{A m}{B}}=-\eta \frac{d \log \frac{N_{H}}{N_{L}}}{d \log \frac{A m}{B}}=\frac{-\eta \lambda H\left(N_{H T}+N_{L L}\right)}{\left(\mu \frac{(1-\lambda) N_{H}}{N_{H T}} N_{L}+\left(\eta-\eta_{L} \frac{\lambda H}{N_{H T}}\right) N_{L L}+\eta_{H} \lambda H\right) N_{H T}}<0
\end{gathered}
$$

where

$$
\begin{gathered}
\eta=-\frac{d \log \frac{W_{H}}{W_{L}}}{d \log \frac{N_{H}}{N_{L}}}=-\frac{d \log h\left(\frac{N_{H}}{N_{L}}\right)}{d \log \frac{N_{H}}{N_{L}}}=\eta_{H}+\eta_{L}>0 \\
\eta_{H}=-\frac{d \log f^{H}}{d \log \frac{N_{H}}{N_{L}}}>0, \eta_{L}=\frac{d \log f^{L}}{d \log \frac{N_{H}}{N_{L}}}>0
\end{gathered}
$$

Furthermore,

$$
\frac{d \log \frac{N_{H T}}{N_{L L}}}{d \log \frac{A m}{B}}=-\frac{\eta}{\mu} \frac{d \log \frac{N_{H}}{N_{L}}}{d \log \frac{A m}{B}}=\frac{-\eta \lambda H\left(N_{H T}+N_{L L}\right)}{\mu\left(\mu \frac{(1-\lambda) N_{H}}{N_{H T}} N_{L}+\left(\eta-\eta_{L} \frac{\lambda H}{N_{H T}}\right) N_{L L}+\eta_{H} \lambda H\right) N_{H T}}<0
$$

and

$$
\frac{d \log \frac{W_{H A}}{W_{L}}}{d \log \frac{A m}{B}}=K\left(\frac{W_{H}-W_{L}}{W_{H}}\left[\frac{\eta}{\mu} N_{L L}+N_{L}\right]-\eta\left(N_{H T}+N_{L L}\right)\right)
$$

where

$$
K=\frac{\lambda \frac{W_{H}}{W_{L}} N_{H} H}{\left[N_{H} \frac{W_{H}-W_{L}}{W_{L}}+N_{H T}\right]\left[\mu \frac{(1-\lambda) N_{H}}{N_{H T}} N_{L}+\left(\eta-\eta_{L} \frac{\lambda H}{N_{H T}}\right) N_{L L}+\eta_{H} \lambda H\right] N_{H T}}>0
$$

One interesting aspect of Proposition 4 is the reversal of the sign of $d \log \frac{N_{H T}}{N_{L L}} / d \log \frac{A m}{B}$ compared to $d \log \frac{N_{H}}{N_{L}} / d \log \frac{A m}{B}$. An increase in $A m / B$ raises the ratio of skilled to unskilled jobs but reduces the ratio of employment of high- to low-skill workers. Putting it differently, the ratios $N_{H T} / N_{L L}$ and $W_{H} / W_{L}$ move together. Secondly, the sign of the expression for $d \log \frac{W_{H A}}{W_{L}} / d \log \frac{A m}{B}$ is ambiguous. If $\eta$ is small - that is, if there is a high elasticity of substitution between high- and low-skill inputs - then the expression 
will be positive and relative wages and employment will move in opposite directions. High values of $\eta$ and $\mu$, on the other hand, will ensure that $d \log \frac{W_{H A}}{W_{L}} / d \log \frac{A m}{B}$ becomes negative, and in this case a decline in $A m / B$ will produce an outcome which fits the observed pattern, at least in a qualitative sense.

Once again, however, the mere possibility that both $W_{H A} / W_{L}$ and $N_{H T} / N_{L L}$ may increase as the result of a fall in $A m / B$ does not establish the empirical relevance of the argument. The parameter conditions may be restrictive or the magnitude of the effects could be negligible for empirically relevant parameter values.

The new parameter in this section is the elasticity, $\mu$, of the real wage with respect to employment. Empirical estimates of this elasticity vary widely but a plausible range for $\mu$ runs from 0.5 to $4 .{ }^{21}$ Using this range for $\mu$ in combination with $\lambda$-values from 0.5 to 0.9 and $\eta$-values from 1 to 4 we get the results in Tables $4-5$. Tables $4 \mathrm{a}-4 \mathrm{~b}$ give the values of $d \log \frac{N_{H T}}{N_{L L}} / d \log \frac{A m}{B}$ and $d \log \frac{W_{H A}}{W_{L}} / d \log \frac{A m}{B}$ for different combinations of $\lambda$ and $\mu$. In these tables the inverse of the elasticity of substitution is assigned the value $\eta=2$. Tables 5a-5b fix $\mu$ at a benchmark level of 2 and allow $\lambda$ and $\eta$ to vary. Both Tables 4 and 5 use US-calibrated values for the initial values of $N_{H T} / H=0.94, N_{L L} / L=0.85$ and $W_{H} / W_{L}=2$ and it is assumed that $\eta_{H}=\eta / 2$.

\footnotetext{
${ }^{21}$ OECD (1994, Table 5.2) gives the semi-elasticity of real wages with respect to unemployment rates for the aggregate labour market in a number of countries. The estimates range from -1 to -10 , with estimates for the US and UK close to -1 and those for most continental European countries and Japan between -3 and -5 . The semi-elasticity is related to the elasticity of real wages with respect to employment: if $u=\frac{L-N}{L}$ is the unemployment rate then

$$
d u=-(1-u)(d \log N-d \log L)
$$

The absolute value of the semi-elasticity exceeds the value of the elasticity $\mu$ both because of the factor $1-u$ and because of the discouraged worker effect which means that changes in the registered labour force are positively correlated with changes in employment.

The relatively low OECD estimate for the semi-elasticity is contradicted by other studies. Card et al (1999) estimate supply elasticities in the 0.2-0.4 range in a disaggregated setup, implying $\mu$-values between 2.5 and 5. Blanchard and Katz (1997) suggest that in the macro data there may be no longterm relation between the unemployment rate and the level of real wage - corresponding to a vertical wage curve or, algebraically, $\mu \rightarrow \infty$ in (25)-(26) - while disaggregated data for the US states imply that the absolute value of the long run semi-elasticity of the real wage with respect to the unemployment rate is well above 5 .
} 
Table 4: The values of $d \log \frac{N_{H T}}{N_{L L}} / d \log \frac{A m}{B}$ and $d \log \frac{W_{H A}}{W_{L}} / d \log \frac{A m}{B}$ for $\eta=2, \eta_{H}=1, W_{H} / W_{L}=2$ and different values of $\lambda$ and $\mu$.

\begin{tabular}{rrrrrrrrrrr}
\multicolumn{1}{c}{$4 \mathrm{a}: d \log \frac{N_{H T}}{N_{L L}} / d \log \frac{A m}{B}$} & \multicolumn{4}{c}{$4 \mathrm{~b}: d \log \frac{W_{H A}}{W_{L}} / d \log \frac{A m}{B}$} \\
$\lambda \backslash \mu$ & 0.5 & 1 & 2 & 4 & $\lambda \backslash \mu$ & 0.5 & 1 & 2 & 4 \\
0.5 & -1.94 & -0.88 & -0.37 & -0.14 & 0.5 & -0.37 & -0.54 & -0.53 & -0.43 \\
0.6 & -2.37 & -1.09 & -0.47 & -0.18 & 0.6 & -0.44 & -0.65 & -0.67 & -0.56 \\
0.7 & -2.82 & -1.32 & -0.59 & -0.24 & 0.7 & -0.50 & -0.76 & -0.80 & -0.71 \\
0.8 & -3.28 & -1.57 & -0.72 & -0.31 & 0.8 & -0.52 & -0.82 & -0.90 & -0.85 \\
0.9 & -3.78 & -1.86 & -0.90 & -0.42 & 0.9 & -0.37 & -0.63 & -0.74 & -0.76
\end{tabular}

Table 5: The value of $d \log \frac{N_{H T}}{N_{L L}} / d \log \frac{A m}{B}$ and $d \log \frac{W_{H A}}{W_{L}} / d \log \frac{A m}{B}$ for $\mu=2, \eta_{H}=\eta / 2, W_{H} / W_{L}=2$ and different values of $\lambda$ and $\eta$.

\begin{tabular}{rrrrrrrrrrr}
\multicolumn{1}{c}{$5 \mathrm{a}: d \log \frac{N_{H T}}{N_{L L}} / d \log \frac{A m}{B}$} & \multicolumn{4}{c}{$5 \mathrm{~b}: d \log \frac{W_{H A}}{W_{L}} / d \log \frac{A m}{B}$} \\
$\lambda \backslash \eta$ & 1 & 2 & 3 & 4 & $\lambda \backslash \eta$ & 1 & 2 & 3 & 4 \\
0.5 & -0.28 & -0.37 & -0.41 & -0.44 & 0.5 & -0.33 & -0.53 & -0.63 & -0.69 \\
0.6 & -0.38 & -0.47 & -0.52 & -0.54 & 0.6 & -0.43 & -0.67 & -0.78 & -0.84 \\
0.7 & -0.48 & -0.59 & -0.63 & -0.66 & 0.7 & -0.53 & -0.80 & -0.92 & -0.99 \\
0.8 & -0.63 & -0.72 & -0.76 & -0.79 & 0.8 & -0.62 & -0.90 & -1.02 & -1.08 \\
0.9 & -0.85 & -0.90 & -0.92 & -0.93 & 0.9 & -0.50 & -0.74 & -0.82 & -0.87
\end{tabular}

The tables show that

- $N_{H T} / N_{L L}$ and $W_{H A} / W_{L}$ move in the same direction for all parameter combinations in the two tables.

- using the values $\lambda=0.8$ and $\eta=2$, which in section 3 gave a perfect fit for the US when changes in employment were taken as exogenous, the rough equality in the empirical data between $d \log N_{H T} / N_{L L}$ and $d \log W_{H T} / W_{L}$ is obtained for a $\mu$-value just under 2 .

- when $\lambda=0.8, \eta=2$ and $\mu=2$, a 20-25 percent fall in $A m / B$ could account for the observed changes in $N_{H T} / N_{L L}$ and $W_{H A} / W_{L}$ in the US. 
A drop of 20-25 percent in $A m / B$ may seem large. Annual labour productivity growth in the US, however, was down 1.2 percentage points in 1973-96 compared with 1950-73 while real wage growth for men dropped by about 3 percentage points (Maddison (1997, Table 11), Gottschalk (1997, p. 25)). The cumulative effects of these changes in the wage trend quickly add up - the real wage would have been almost twice as high in 1996 if the trend had been unchanged - and could cause a significant drop in $A m / B$ if wage aspirations (as measured by the time path for B) adjust slowly.

The German case, in which low-skill workers experienced a deterioration of their relative employment position but a slight improvement in the relative wage, is harder to explain. With exogenous employment changes, a good fit was obtained in section 3 for $\eta=2$ and a $\lambda$-value between 0.5 and 0.6. Given the specification in (25)-(26) of the supply side of the labour market, however, the changes in employment and relative wages cannot both be accounted for by a decline in $A m / B \cdot{ }^{22}$ Using $\eta=2, \mu=2$ and $\lambda=0.5$ (reflecting the less flexible labour market), a fall of $20-25$ percent in $A m / B$ would generate a rise of just under 10 percent in $N_{H T} / N_{L L}$, which is in line with the evidence, but an increase of over 10 percent in $W_{H A} / W_{L}$.

\section{Conclusions}

It is commonly believed that skill-biases in technical change and/or changes in the relative supplies are needed in order to produce a pattern in which high-skill workers do better than low-skill workers in terms of both employment and wages. The argument in this paper challenges this view.

The US pattern is particularly striking and, not surprisingly, the US experience has been the main focus of debate. In this paper we have argued that using plausible parameter values, the broad US pattern may even be consistent with the absence of skill-biases and with an unchanged pattern of labour supply (or, more realistically, with unchanged trend increases in the skill requirements and the supplies of skill). The mechanism behind our argument is exceedingly simple: some high-skill workers who fail to get high-skill jobs will move into low-skill jobs. Once this possibility is recognized, the observed changes in the employment rates of high and low-skill workers generate increasing wage inequality, both within and between skill categories. The mechanism,

\footnotetext{
${ }^{22}$ Tables 4-5 are constructed using US observations for the initial values of $N_{H T} / H, N_{L L} / L$ and $W_{H} / W_{L}$. A recalculation based on German initial values has only minor effects and does not change the qualititative picture.
} 
moreover, is consistent with the observation that the change in relative employment has occurred within industries and does not reflect a structural shift away from low-skill industries.

The changes in employment in turn may be related, at least in part, to the productivity slowdown that occurred around 1970. Thus, our argument links changes in unemployment and wage inequality to productivity movements in a highly parsimonious way: a single (unexplained) change - the productivity slowdown - is used to account for the observed increase in both unemployment and inequality between 1970 and the early 1990s. Furthermore, the model correctly predicts that recent increases in productivity growth will be associated with reductions in unemployment and inequality.

One may question the magnitude and durability of the effects of changes in productivity growth on the ratio $A m / B$. It should be noted, however, that reservations in this respect concern the specification of the supply side of the labour market and have no bearing on the need for skill-biassed technical change to generate the observed trends in unemployment and wage inequality. Given the extent to which high-skill workers accept low-skill jobs (the value of $\lambda$ ) and the elasticity of substitution (the inverse of $\eta)$ it is possible to trace the implied effects of exogenous employment changes on the relative wage. As shown in section 3 , the changes in relative wages are consistent with the observed employment changes for plausible values of the critical parameters $\lambda$ and $\eta$.

The effects highlighted in this paper do not exclude other influences on inequality. International competition, skill-biases in technical progress and changes in labour market institutions may all have contributed to the observed trends in wage inequality and in the level and composition of unemployment. ${ }^{23}$ In fact, our results implicitly support the view that institutional differences on the supply side of the labour market play an important role. Thus, in section 4 the German evidence could not be explained using a labour supply specification that seemed to work reasonably well for the US. If differences

\footnotetext{
${ }^{23}$ Supporters of skill-biased technical change suggest that the absence of other convincing explanations "implicates technology by default" with direct evidence coming from "strong correlations that withinindustry upgrading has with both R\&D investment and the increase in computer investments" (Berman et al (1994, p. 391-2)). With industry-specific shocks, however, shifts in employment will not be uniform and it is not surprising that the shifts have been particularly strong in industries with high R\&D and high computer investment: if technologically advanced industries tend to be relatively skill-intensive, then technologically dynamic industries will experience an above-average shift towards high-skill workers. Thus, the observed correlation is consistent with many different explanations of the average shift towards high-skill workers and the default argument is weakened by the skill-asymmetry effects outlined here.
} 
in wage setting institutions are important from a cross-section perspective then changes in these institutions should play a role in a time-series perspective. Many countries have experienced significant changes in their labour market institutions since 1970 and it would be surprising if these developments had left no mark on unemployment or inequality.

Even if one were to disregard the possible, complementary influences of skill-biases, international trade and wage-setting institutions, the model has left out many complicating factors. It has been assumed, for instance, that the supplies of $H$ and $L$ are constant while in reality, changes in the (trend increase of) supply of skill and in the quality of formal education may well have contributed to the observed cross-sectional and time-series patterns for relative wages and unemployment. The assumption of only two skill categories clearly involves another drastic simplification as does the assumption of homogeneity of all workers within a skill category. This latter assumption precludes the possibility that measured overeducation reflects unobserved quality differences among workers. Yet another set of limitations is our neglect of undereducation and the use of a simple "job-competition model" in which low-skill workers cannot perform high-skill jobs while high- and low-skill workers are perfect substitutes in low-skill jobs. ${ }^{24}$ These simplifying assumptions are contradicted by the co-existence in the data of both underand overeducation and by the consistent finding that overeducated workers get some wage premium. ${ }^{25}$ Finally, our stylized facts presented a crude picture of the available evidence and the numerical calculations are merely indicative.

These limitations notwithstanding, the analysis highlights a mechanism which has not received little or no attention in the recent literature on changes in wage inequality. Using a formalization which deliberately has left out skill-biases, international compe-

\footnotetext{
${ }^{24}$ In a more general specification the high skill input $N_{H}$ could be written as

$$
N_{H}=N_{H}\left(N_{H H}, N_{H L}\right)
$$

where $N_{H H}$ and $N_{H L}$ denote the employment of high and low skill workers, respectively, in high skill positions. Analogously, the low skill input would be

$$
N_{L}=N_{L}\left(N_{L L}, N_{L H}\right)
$$

This general specification, which allows undereducation and which does not require perfect substitution between high and low skill workers in low skill positions, contains our specification in the paper as a special case.

${ }^{25}$ General assignment models would leave a role for the characteristics of both the job and the worker in the determination of productivity and wages (Sattinger (1993)).
} 
tition and institutional changes, we have shown that the effects of skill asymmetries, induced overeducation and credentialism may be empirically relevant and that they deserve further empirical examination.

\section{Appendices}

\subsection{Appendix A: Proof of proposition 1}

Substituting (2) into (5) and (3) into (6) we get

$$
\begin{gathered}
B g^{H}\left(N_{H}\right)=A m f^{H}\left(\frac{N_{H}}{N_{L}}\right) ; g^{H \prime}>0, f^{H \prime}<0 \\
B g^{L}\left(N_{L}\right)=A m f^{L}\left(\frac{N_{H}}{N_{L}}\right) ; g^{L \prime}>0, f^{L \prime}>0
\end{gathered}
$$

Equation (A1) implies that $N_{H}$ is an increasing function of $A m / B$ and $N_{L}$ and that $N_{H} / N_{L}$ is increasing in $A m / B$ but decreasing in $N_{L}$,

$$
\begin{gathered}
N_{H}=N_{H}\left(\frac{A m}{B}, N_{L}\right) ; N_{H 1}>0, N_{H 2}>0 \\
\frac{N_{H}}{N_{L}}=\frac{N_{H}}{N_{L}}\left(\frac{A m}{B}, N_{L}\right) ; \frac{N_{H}}{N_{L} 1}>0, \frac{N_{H}}{N_{L} 2}<0
\end{gathered}
$$

Substituting (A4) into (A2) yields

$$
g^{L}\left(N_{L}\right)=\frac{A m}{B} f^{L}\left(\frac{N_{H}}{N_{L}}\left(\frac{A m}{B}, N_{L}\right)\right)
$$

Given the signs of the partial derivatives, we now get

$$
N_{L}=N_{L}\left(\frac{A m}{B}\right) ; N_{L}^{\prime}>0
$$

and - using (A3) and (A6) -

$$
N_{H}=N_{H}\left(\frac{A m}{B}\right) ; N_{H}^{\prime}>0
$$

The effects on $N_{H}$ and $N_{L}$ of changes in the parameters follow directly from (A6)-(A7).

In order to get the effects on $W_{H} / P$ and $W_{L} / P$ we combine (A6)-(A7) with (2)-(3) and (5)-(6). Equations (5) and (A7) imply that $W_{H} / P$ is increasing in $A$ and $m$; the 
analogous result for $W_{L} / P$ follows from (6) and (A6). Equations (2) and (3) imply that changes in $B$ will affect the wage rates only insofar as they cause the ratio $N_{H} / N_{L}$ to change. Since changes in the labour ratio affect $W_{H} / P$ and $W_{L} / P$ in opposite directions the result follows: an increase in $B$ will lead to a reduction in both $N_{H}$ and $N_{L}$ but affect $W_{H} / P$ and $W_{L} / P$ in opposite directions. We have now proved (i) and (ii). The result in (iii) follows directly from equation (4) and hence is independent of the specification in equations (5)-(6) of the bargained real wage.

\subsection{Appendix B: Proof of proposition 2}

Equations (13)-(14) follow from (10) and the definitions in (7)-(9), and equations (15)(16) can be derived by logarithmic differentiation of (13)-(14), noting that by assumption the labour supply $H$ is constant.

Turning to (17), the definition of the relative wage is given by

$$
\frac{W_{H A}}{W_{L}}=\frac{W_{H} N_{H}+W_{L} N_{L H}}{N_{H T} W_{L}}=\frac{W_{H} N_{H}+W_{L} \lambda\left(H-N_{H}\right)}{\left(N_{H}+\lambda\left(H-N_{H}\right)\right) W_{L}}=\frac{\omega N_{L}+\lambda\left(H-N_{H}\right)}{N_{H}+\lambda\left(H-N_{H}\right)}
$$

where

$$
\omega=\frac{W_{H} N_{H}}{W_{L} N_{L}}
$$

The ratio $\omega$ represents the relative income shares of high and low-skill inputs and we have

$$
\begin{aligned}
d \log \omega & =\frac{d \log \omega}{d \log \frac{N_{H}}{N_{L}}} d \log \frac{N_{H}}{N_{L}} \\
& =(-\eta+1) d \log \frac{N_{H}}{N_{L}}
\end{aligned}
$$

Taking logs and differentiating (B1) we get

$$
\begin{aligned}
d \log \frac{W_{H A}}{W_{L}}= & d \log \left(\omega N_{L}+\lambda\left(H-N_{H}\right)\right)-d \log \left(N_{H}+\lambda\left(H-N_{H}\right)\right) \\
= & \frac{1}{D}\left[\omega N_{L}\left(d \log \omega+d \log N_{L}\right)-\lambda N_{H} d \log N_{H}\right] \\
& -\frac{1}{N_{H T}} N_{H}(1-\lambda) d \log N_{H} \\
= & \frac{\omega N_{L}}{D}\left[\begin{array}{c}
(-\eta+1) d \log \frac{N_{H}}{N_{L}}+d \log N_{L}-\frac{\lambda N_{H}}{\omega N_{L}} d \log N_{H} \\
-\frac{D}{N_{H T}} \frac{N_{H}}{\omega N_{L}}(1-\lambda) d \log N_{H}
\end{array}\right]
\end{aligned}
$$




$$
\begin{aligned}
& =\frac{\omega N_{L}}{D}\left[\eta d \log N_{L}+\left(1-\eta-\lambda \frac{W_{L}}{W_{H}}-\frac{D}{N_{H T}} \frac{W_{L}}{W_{H}}(1-\lambda)\right) d \log N_{H}\right] \\
& =\frac{\omega N_{L}}{D}\left[\left(-\eta+\frac{\left(1-\lambda \frac{W_{L}}{W_{H}}\right) N_{H T}-(1-\lambda) \frac{W_{L}}{W_{H}} D}{N_{H T}}\right) d \log N_{H}\right] \\
& =\frac{\omega N_{L}}{D}\left[\eta d \log N_{L}+\left(-\eta+\frac{W_{H}-W_{L}}{W_{H}} \frac{\lambda H}{N_{H T}}\right) d \log N_{H}\right] \\
& =\frac{\frac{W_{H}}{W_{L}} N_{H}}{\frac{W_{H}-W_{L}}{W_{L}} N_{H}+N_{H T}}\left[\begin{array}{c}
\eta d \log N_{L}+ \\
\left(-\eta+\frac{W_{H}-W_{L}}{W_{H}} \frac{\lambda H}{N_{H T}}\right) d \log N_{H}
\end{array}\right]
\end{aligned}
$$

where

$$
D=\omega N_{L}+\lambda\left(H-N_{H}\right)=\frac{W_{H}-W_{L}}{W_{L}} N_{H}+N_{H T}>0
$$

In order to derive (18) we note first that the expression for $\sigma$ can be rewritten using the definitions of $W_{H A}, N_{L H}$ and $N_{H T}$ :

$$
\begin{aligned}
\sigma & =\frac{W_{H A}-W_{L}}{W_{H A}} \sqrt{\frac{N_{H}}{N_{H T}}\left(\frac{W_{H}-W_{H A}}{W_{H A}-W_{L}}\right)^{2}+\frac{N_{L H}}{N_{H T}}} \\
& =\left(1-\frac{W_{L}}{W_{H A}}\right) \sqrt{\frac{N_{H}}{N_{H T}}\left(\frac{W_{H}-\frac{N_{H}}{N_{H T}} W_{H}-\frac{N_{L H}}{N_{H T}} W_{L} W_{H}+\frac{N_{L H}}{N_{H T}} W_{L}-W_{L}}{N_{H T}}+\frac{N_{L H}}{N_{H T}}\right.} \\
& =\left(1-\frac{W_{L}}{W_{H A}}\right) \sqrt{\frac{N_{H}}{N_{H T}}\left(\frac{N_{L H}}{N_{H}}\right)^{2}+\frac{N_{L H}}{N_{H T}}} \\
& =\left(1-\frac{W_{L}}{W_{H A}}\right) \sqrt{\frac{N_{L H}}{N_{H}}} \\
& =\left(1-\frac{W_{L}}{W_{H A}}\right) \sqrt{\frac{\lambda\left(H-N_{H}\right)}{N_{H}}}
\end{aligned}
$$

Hence,

$$
\begin{aligned}
d \log \sigma & =d \log \left(1-\frac{W_{L}}{W_{H A}}\right)+\frac{1}{2}\left[d \log \left(\lambda\left(H-N_{H}\right)\right)-d \log N_{H}\right] \\
& =\frac{W_{H A}}{W_{H A}-W_{L}}\left(-\frac{W_{L}}{W_{H A}}\right) d \log \frac{W_{L}}{W_{H A}}+\frac{1}{2}\left[\frac{-\lambda N_{H}}{\lambda\left(H-N_{H}\right)} d \log N_{H}-d \log N_{H}\right] \\
& =\frac{W_{L}}{W_{H A}-W_{L}} d \log \frac{W_{H A}}{W_{L}}-\frac{1}{2} \frac{H}{H-N_{H}} d \log N_{H}
\end{aligned}
$$




\subsection{Appendix C: Proof of proposition 3}

\subsection{1 (i) Existence of equilibrium}

Using equations (9)-(10), equations (22) and (24) can be rewritten

$$
\begin{gathered}
\frac{W_{H}}{P}=B g^{H}\left(\frac{N_{H}}{H}, \frac{\lambda\left(H-N_{H}\right)}{H}, \frac{W_{L}}{P}\right) \\
=B G^{H}\left(\frac{N_{H}}{H}, \frac{W_{L}}{P}\right) ; G_{1}^{H}=g_{1}^{H}-\lambda g_{2}^{H}>g_{1}^{H}-g_{2}^{H}>0, G_{2}^{H}>0 \\
\frac{W_{L}}{P}=B g^{L}\left(\frac{N_{L L}}{L}\right)=B g^{L}\left(\frac{N_{L}-\lambda\left(H-N_{H}\right)}{L}\right) \\
=B G^{L}\left(\frac{N_{L}}{L}, \frac{N_{H}}{L}\right) ; G_{1}^{L}=g^{L \prime}>0, G_{2}^{L}=\lambda g^{L \prime}>0
\end{gathered}
$$

Combining these equations with (2)-(3) yields

$$
\begin{gathered}
G^{H}\left(\frac{N_{H}}{H}, A m f^{L}\left(\frac{N_{H}}{N_{L}}\right)\right)=\frac{A m}{B} f^{H}\left(\frac{N_{H}}{N_{L}}\right) ; G_{1}^{H}>0, G_{2}^{H}>0, f^{L \prime}>0, f^{H \prime}<0 \\
G^{L}\left(\frac{N_{L}}{L}, \frac{N_{H}}{L}\right)=\frac{A m}{B} f^{L}\left(\frac{N_{H}}{N_{L}}\right) ; G_{1}^{L}>0, G_{2}^{L}>0, f^{L}>0
\end{gathered}
$$

Equation (C3) and the signs of the partial derivatives imply that $N_{H}$ is an increasing function of $N_{L}$ while the ratio $N_{H} / N_{L}$ is a decreasing function of $N_{L}$. Combining these results with equation (C4) - and using the signs of the partial derivatives of $G^{L}$ and $f^{L}$ - gives a unique solution for $N_{L}^{*}$ and $N_{H}^{*}$. Equations (9) and (10) can now be used to give unique solutions for $N_{L H}^{*}$ and $N_{L L}^{*}$ while equations (22) and (24) determine $W_{H}^{*} / P$ and $W_{L}^{*} / P$.

In order to ensure non-negative solution values for $N_{H}$ and $N_{L L}$, the solution is defined as $N_{H}=0$ if $G^{H}\left(0, A m f^{L}(0)\right)>\frac{A m}{B} f^{H}(0)$ and as $N_{L L}=0$ if $G^{L}\left(\frac{\lambda\left(H-N_{H}\right)}{L}, \frac{N_{H}}{L}\right)>$ $\frac{A m}{B} f^{L}\left(\frac{N_{H}}{\lambda\left(H-N_{H}\right)}\right)$. The asymptotic conditions on $g^{H}$ and $g^{L}$ (see footnote 17) imply that $G^{H}\left(\frac{N_{H}}{H}, A m f^{L}\left(\frac{N_{H}}{N_{L}}\right)\right) \rightarrow \infty$ for $N_{H} \rightarrow H$ and that $G^{L}\left(\frac{N_{L}}{L}, \frac{N_{H}}{L}\right) \rightarrow \infty$ for $\left(N_{L}-\lambda\left(H-N_{H}\right)\right) \rightarrow L$ and hence ensure that $N_{L L}<L$ and $N_{H}<H$.

\subsection{2 (ii) Effects of changes in $A m$ or $B$}

Note first that $N_{L}$ and $N_{H}$ cannot both decrease as $A m$ increases or $B$ decreases. To see this, substitute $(\mathrm{C} 2)$ for $W_{L} / P$ in $(\mathrm{C} 1)$ and use $(2)$ to get

$$
G^{H}\left(\frac{N_{H}}{H}, B G^{L}\left(\frac{N_{L}}{H}, \frac{N_{H}}{H}\right)\right)=\frac{A m}{B} f^{H}\left(\frac{N_{H}}{N_{L}}\right) ; G_{1}^{H}>0, G_{2}^{H}>0, f^{L \prime}>0, f^{H \prime}<0
$$


Now observe that a decline in both $N_{L}$ and $N_{H}$ would imply that the values on the left hand side of both (C4) and (C5) will decrease. The right hand sides of (C4) and (C5), on the other hand, cannot both decline as $A m$ increases or $B$ decreases. It follows that $N_{L}$ and/or $N_{H}$ must increase. Since equation (C5) implies that $N_{H}$ is increasing in $A m$ and decreasing in $B$ and since we know from (i) that $N_{H}$ is increasing in $N_{L}$, an increase in $N_{L}$ would also cause $N_{H}$ to go up. It follows that a rise in $A m$ or a fall in $B$ must lead to an increase in $N_{H}$.

Since (2) and (3) continue to hold, finally, so does equation (4). Thus, the movements in relative wages and relative employment must be in opposite directions.

\subsection{3 (iii) Effects of changes in $A m$ or $B$ in the symmetric case}

Assume that a rise in $A m$ or a decline in $B$ caused $N_{H} / N_{L}$ to decrease and hence - using (4) - that $W_{H} / W_{L}$ increases. We show that this assumption leads to a contradiction.

We know from (ii) that $N_{H}$ increases and since, by assumption, $N_{H} / N_{L}$ decreases, we have $d \log N_{L}>d \log N_{H}>0$. Since $N_{L}=N_{L L}+N_{L H}$ and $N_{H}=N_{H T}-N_{L H}$, and since $N_{L H}$ is a decreasing function of $N_{H}$ it follows that $d \log N_{L L}>d \log N_{L}>d \log N_{H}>$ $d \log N_{H T}$.

Using (7)-(10), equation (22) can be written

$$
\begin{aligned}
\frac{W_{H}}{P} & =B g^{H}\left(\frac{N_{H T}-\lambda H}{(1-\lambda) H}, \frac{\lambda H-\lambda N_{H T}}{(1-\lambda) H}, \frac{W_{L}}{P}\right) \\
& =B \varphi\left(N_{H T}, \frac{W_{L}}{P}\right) ; \varphi_{1}=g_{1}^{H} \frac{1}{(1-\lambda) H}-g_{2}^{H} \frac{\lambda}{(1-\lambda) H}>0
\end{aligned}
$$

Logarithmic differentiation of (C6) implies that

$$
d \log \frac{W_{H}}{P}=d \log B+\mu_{1}^{H} d \log N_{H T}+\mu_{2}^{H} d \log \frac{W_{L}}{P}
$$

where $\mu_{1}^{H}$ and $\mu_{2}^{H}$ are the partial elasticities of $W_{H} / P$ with respect to $N_{H T}$ and $W_{L} / P$. Analogously, using (24),

$$
d \log \frac{W_{L}}{P}=d \log B+\mu^{L} d \log N_{L L}
$$

where $\mu^{L}$ is the elasticity of $W_{L} / P$ with respect to $N_{L L}$. By assumption, a proportionate increase in $N_{H T}$ and $N_{L L}$ leaves the relative wage unchanged. Hence,

$$
\mu_{1}^{H}+\mu_{2}^{H} \mu^{L}=\mu^{L}
$$


Using (C7)-(C9) we get

$$
\begin{aligned}
d \log \frac{W_{H}}{W_{L}} & =\mu_{1}^{H} d \log N_{H T}+\mu_{2}^{H} \mu^{L} d \log N_{L L}-\mu^{L} d \log N_{L L} \\
& =\mu_{1}^{H}\left(d \log N_{H T}-d \log N_{L L}\right)
\end{aligned}
$$

and hence, using $d \log N_{L L}>d \log N_{L}>d \log N_{H}>d \log N_{H T}$,

$$
d \log \frac{W_{H}}{W_{L}}<0
$$

By assumption, however, $d \log W_{H} / W_{L}>0$, and we have a contradiction. It follows that $N_{H} / N_{L}$ must increase following an increase in $A m$ or a decrease in $B$.

\subsection{Appendix D: Proof of proposition 4}

\subsubsection{Derivation of the expression for $d \log \frac{N_{H}}{N_{L}} / d \log \frac{A m}{B}$}

Combining (2)-(3) and (25)-(26) we get

$$
\begin{aligned}
& N_{H T}^{\mu}=\frac{A m}{B} f^{H}\left(\frac{N_{H}}{N_{L}}\right) \\
& N_{L L}^{\mu}=\frac{A m}{B} f^{L}\left(\frac{N_{H}}{N_{L}}\right)
\end{aligned}
$$

Taking logs and differentiating, we get

$$
\begin{aligned}
& \mu d \log N_{H T}=d \log \frac{A m}{B}+\frac{d \log f^{H}}{d \log \frac{N_{H}}{N_{L}}}\left(d \log N_{H}-d \log N_{L}\right) \\
& \mu d \log N_{L L}=d \log \frac{A m}{B}+\frac{d \log f^{L}}{d \log \frac{N_{H}}{N_{L}}}\left(d \log N_{H}-d \log N_{L}\right)
\end{aligned}
$$

Using equations (9) and (10) and the definitions of $\eta, \eta_{L}$ and $\eta_{H}$, equations (D3)-(D4) can be rewritten

$$
\begin{gathered}
\left(\mu \frac{(1-\lambda) N_{H}}{N_{H T}}+\eta_{H}\right) d \log N_{H}=d \log \frac{A m}{B}+\eta_{H} d \log N_{L} \\
\frac{\mu}{N_{L L}}\left(N_{L} d \log N_{L}+\lambda N_{H} d \log N_{H}\right)=d \log \frac{A m}{B}+\eta_{L}\left(d \log N_{H}-d \log N_{L}\right)
\end{gathered}
$$

Solving (D5) for $d \log N_{H}$ and substituting into (D6), we get 


$$
\begin{aligned}
& \left(\frac{\mu N_{L}+\frac{\eta_{H}}{\mu \frac{(1-\lambda) N_{H}}{N_{H T}}+\eta_{H}} \mu \lambda N_{H}}{N_{L L}}+\frac{\mu \frac{(1-\lambda) N_{H}}{N_{H T}}}{\mu \frac{(1-\lambda) N_{H}}{N_{H T}}+\eta_{H}} \eta_{L}\right) d \log N_{L} \\
& =d \log \frac{A m}{B}\left(1+\frac{\eta_{L}}{\mu \frac{(1-\lambda) N_{H}}{N_{H T}}+\eta_{H}}-\frac{\frac{\mu}{\mu \frac{(1-\lambda) N_{H}}{N_{H T}}+\eta_{H}} \lambda N_{H}}{N_{L L}}\right)
\end{aligned}
$$

or

$$
d \log N_{L}=\frac{\eta N_{L L}+\mu N_{L}-\mu \lambda H \frac{N_{H T}+N_{L L}}{N_{H T}}}{\mu\left(\left(\eta-\eta_{L} \frac{\lambda H}{N_{H T}}\right) N_{L L}+\mu \frac{(1-\lambda) N_{H}}{N_{H T}} N_{L}+\lambda \eta_{H} H\right)} d \log \frac{A m}{B}
$$

Equation (D5) can be rewritten

$$
\left(\mu \frac{(1-\lambda) N_{H}}{N_{H T}}+\eta_{H}\right)\left(d \log N_{H}-d \log N_{L}\right)=d \log \frac{A m}{B}-\mu \frac{(1-\lambda) N_{H}}{N_{H T}} d \log N_{L}
$$

or

$$
d \log \frac{N_{H}}{N_{L}}=\frac{1}{\mu \frac{(1-\lambda) N_{H}}{N_{H T}}+\eta_{H}} d \log \frac{A m}{B}-\frac{\mu \frac{(1-\lambda) N_{H}}{N_{H T}}}{\mu \frac{(1-\lambda) N_{H}}{N_{H T}}+\eta_{H}} d \log N_{L}
$$

Substituting the expression for $d \log N_{L}$ - equation (D8) - into (D10) we now get

$$
d \log \frac{N_{H}}{N_{L}}=\frac{\lambda H\left(N_{H T}+N_{L L}\right) d \log \frac{A m}{B}}{\left(\left(\eta-\eta_{L} \frac{\lambda H}{N_{H T}}\right) N_{L L}+\mu \frac{(1-\lambda) N_{H}}{N_{H T}} N_{L}+\lambda \eta_{H} H\right) N_{H T}}
$$

Equation (D11) can be rewritten as (27) in the proposition.

6.4.2 Derivation of the expression for $d \log \frac{W_{H}}{W_{L}} / d \log \frac{A m}{B}$ and $d \log \frac{N_{H T}}{N_{L L}} / d \log \frac{A m}{B}$ To find $d \log \frac{W_{H}}{W_{L}} / d \log \frac{A m}{B}$ and $d \log \frac{N_{H T}}{N_{L L}} / d \log \frac{A m}{B}$, use (4) and (25)-(26), respectively, in combination with (D11) to get

$$
\begin{aligned}
d \log \frac{W_{H}}{W_{L}} & =d \log h\left(\frac{N_{H}}{N_{L}}\right)=-\eta d \log \frac{N_{H}}{N_{L}} \\
& =\frac{-\eta \lambda H\left(N_{H T}+N_{L L}\right) d \log \frac{A m}{B}}{\left(\left(\eta-\eta_{L} \frac{\lambda H}{N_{H T}}\right) N_{L L}+\mu \frac{(1-\lambda) N_{H}}{N_{H T}} N_{L}+\lambda \eta_{H} H\right) N_{H T}}
\end{aligned}
$$

and

$$
\begin{aligned}
d \log \frac{N_{H T}}{N_{L L}} & =\frac{1}{\mu} d \log \frac{W_{H}}{W_{L}} \\
& =\frac{-\eta \lambda H\left(N_{H T}+N_{L L}\right) d \log \frac{A m}{B}}{\mu\left(\left(\eta-\eta_{L} \frac{\lambda H}{N_{H T}}\right) N_{L L}+\mu \frac{(1-\lambda) N_{H}}{N_{H T}} N_{L}+\lambda \eta_{H} H\right) N_{H T}}
\end{aligned}
$$




\subsubsection{Derivation of $d \log \frac{W_{H A}}{W_{L}} / d \log \frac{A m}{B}$}

Equation (17) in Proposition 2 gives an expression for $d \log \frac{W_{H A}}{W_{L}}$ in terms of $d \log N_{H}$ and $d \log N_{L}$. Using this equation in combination with (D8) and (D11) we get

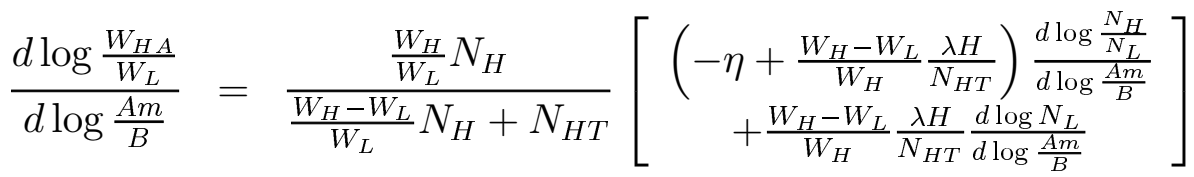

$$
\begin{aligned}
& =M\left[\begin{array}{c}
\left(-\eta+\frac{W_{H}-W_{L}}{W_{H}} \frac{\lambda H}{N_{H T}}\right) \frac{\lambda H\left(N_{H T}+N_{L L}\right)}{\left(\left(\eta-\eta_{L} \frac{\lambda H}{N_{H T}}\right) N_{L L}+\mu \frac{(1-\lambda) N_{H}}{\left.N_{H} N_{L}+\lambda \eta_{H} H\right) N_{H T}}\right.} \\
+\frac{W_{H}-W_{L}}{W_{H}} \frac{\lambda H}{N_{H T}} \frac{\eta N_{L L}+\mu N_{L}-\mu \lambda H \frac{N_{H T}+N_{L L}}{N_{H T}}}{\mu\left(\left(\eta-\eta_{L} \frac{\lambda H}{N_{H T}}\right) N_{L L}+\mu \frac{(1-\lambda) N_{H}}{N_{H T}} N_{L}+\lambda \eta_{H} H\right)}
\end{array}\right] \\
& =M \frac{\lambda H\left[\frac{W_{H}-W_{L}}{W_{H}}\left(\frac{\eta}{\mu} N_{L L}+N_{L}\right)-\eta\left(N_{H T}+N_{L L}\right)\right]}{\left(\left(\eta-\eta_{L} \frac{\lambda H}{N_{H T}}\right) N_{L L}+\mu \frac{(1-\lambda) N_{H}}{N_{H T}} N_{L}+\lambda \eta_{H} H\right) N_{H T}}
\end{aligned}
$$

where

$$
M=\frac{\frac{W_{H}}{W_{L}} N_{H}}{\frac{W_{H}-W_{L}}{W_{L}} N_{H}+N_{H T}}
$$

\section{References}

[1] Autor, D, Katz, L. and Krueger, A. (1998) "Computing Inequality: Have Computers Changed the Labour Market". Quarterly Journal of Economics, 113, pp. 1169-1213.

[2] Berman, E., Bound, J. and Griliches, Z. (1994) "Changes in the Demand for Skilled Labor within US Manufacturing: Evidence from the Annual Survey of Manufactures". Quarterly Journal of Economics, 109, pp. 367-397.

[3] Bewley, T.F. (1998) "Why Not Cut Pay?". European Economic Review, 42 (3-5), pp. 459-490.

[4] Blanchard, O. (1998) "Revisiting European Unemployment: Unemployment, Capital Accumulation and Factor Prices". NBER Working Paper 6566.

[5] Blanchard, O. and Katz, L.F. (1997) "What We Know and Do Not Know About the Natural Rate of Unemployment". Journal of Economic Perspectives, 11:1, pp. 51-72. 
[6] Blank, R.M. (2000) "Distinguished Lecture on Economics in Government - Fighting Poverty: Lessons from Recent US History". Journal of Economic Perspectives, 14 (2), pp 3-19.

[7] Blinder, A. and Esaki, H. (1978) "Macroeconomic Activity and Income Distribution in the Postwar United States". Review of Economics and Statistics, 60, pp. 604-609.

[8] Bresnahan, T.F. (1999) "Computerisation and Wage Dispersion: an Analytical Reinterpretation". Economic Journal, 109, June, F390-F415.

[9] Carlin, W. and Soskice, D. (1990) Macroeconomics and the Wage Bargain. Oxford University Press.

[10] Card, D., Kramarz, F. and Lemieux, T. (1999) "Changes in the Relative Structure of Wages and Employment: A Comparison of the United States, Canada and France". Canadian Journal of Economics, 32 (4), pp. 843-877.

[11] Daly, M.C., Büchel, F. and Duncan, G.J. (2000) "Premiums and Penalties for Surplus and Deficit Education: Evidence from the United States and Germany". Economics of Education Review, 19 (2), pp. 169-178.

[12] Deding, M.C. (2000) "Aspects of Income Distributions in a Labour Market Perspective". PhD thesis 2000-3, Department of Economics, University of Aarhus.

[13] DiNardo, J. Fortin, N.M. and Lemieux, T. (1996) "Labor Market Institutions and the Distribution of Wages, 1973-1992". Econometrica, 65, 1001-44.

[14] Doeringer, P.B. and Piore, M.J. (1971) Internal Labor Markets and Manpower Analysis. Lexington, MA: Heath.

[15] Dolton, P.J. and Vignoles, A. (2000) "The Incidence and Effects of Overeducation in the UK Graduate Labour Market". Economics of Education Review, 19 (2), pp. 179-198.

[16] Feenstra, R.C. and Hanson, G.H. (1999) "The Impact of Outsourcing and HighTechnology Capital on Wages: Estimates for the United States, 1979-90". Quarterly Journal of Economics, 114:3, 907-40.

[17] Fortin, N.M. and Lemieux, T. (1997) "Institutional Changes and Rising Wage Inequality: Is There a Linkage?" Journal of Economic Perspectives, 11:2, 75-96. 
[18] Freeman, R. (1993) "How Much Has De-Unionization Contributed to the Rise in Male Earnings Inequality?". In S. Danziger and P. Gottschalk (eds) Uneven Tides: Rising Inequality in America, New York: Russell Sage Foundation.

[19] Gautier, P. (2000) "Do More High-skilled Workers Occupy Simple Jobs During Bad Times?" In L. Borghans and A. de Grip (eds) The Overeducated worker? The Economics of Skill Utilization, Cheltenham: Edward Elgar.

[20] Gottschalk, P. (1997) "Inequality, Income Growth, and Mobility: The Basic Facts". Journal of Economic Perspectives, 11:2, 21-40.

[21] Green, F., McIntosh, S. and Vignoles, A. (1999) "Overeducation and Skills - Clarifying the Concepts". Centre for Economic Performance Discussion Paper 435, London School of Economics.

[22] Green, F., Felstead, A. and Gallie, D. (2000) "Computers Are Even More Important than You Thought: an Analysis of the Changing Skill-Intensity of Jobs". Centre for Economic Performance Discussion Paper 439, London School of Economics.

[23] Groot, L. and Hoek, A. (2000) "Job Competition in the Dutch Labour Market". In L. Borghans and A. de Grip (eds) The Overeducated worker? The Economics of Skill Utilization, Cheltenham: Edward Elgar.

[24] Groot, W. and Maassen van der Brink, H. (2000) "Overeducation in the Labor Market: A Meta-Analysis". Economics of Education Review, 19 (2), pp. 149-158.

[25] Hartog, J. (2000) "Overeducation and Earnings: Where We Are, Where We Should Go". Economics of Education Review, 19, pp. 131-147.

[26] Hersch, J. (1991) "Education Match and Job Match". Review of Economics and Statistics, 73, pp. 140-144.

[27] Jäntti, M. (1994) "A More Efficient Estimate of the Effects of Macroeconomic Activity on the Distribution of Income. Review of Economics and Statistics, 76, pp. 372-378.

[28] Katz, L.F. and Murphy, K.M. (1992) "Changes in Relative Wages, 1963-1987: Supply and Demand Factors". Quarterly Journal of Economics, 107, pp. 35-78.

[29] Leamer, E. (1994) "Trade, Wages and Revolving Door Ideas “ NBER Working Paper No 4716. 
[30] McKenna, C.J. (1996) "Education and the Distribution of Unemployment". European Journal of Political Economy, 12, pp. 113-132.

[31] Maddison, A. (1997) "The Nature and Functioning of European Capitalism: A Historical and Comparative Perspective". Banca Nazionale del Lavoro Quarterly Review, L:203, 431-479.

[32] Muysken, J. and Ter Weel, B. (2000) "Overeducation and Crowding Out of Lowskilled Workers". In L. Borghans and A. de Grip (eds) The Overeducated worker? The Economics of Skill Utilization, Cheltenham: Edward Elgar.

[33] Murphy, K.M. and Welch, F. (1992) "The Structure of Wages". Quarterly Journal of Economics, 107 (1), pp. 285-326.

[34] Nickell, S. and Bell, B. (1996) "Changes in the Distribution of Wages and Unemployment in OECD Countries". American Economic Review, 86:2, 302-308.

[35] OECD (1994) The OECD Jobs Study. OECD.

[36] Reder, M.W. (1955) "The Theory of Occupational Wage Differentials". American Economic Review, 45:5, pp. 833-852.

[37] Reich, R.B. (1993) American Competitiveness and American Brains. New York: Baruch College, City University of New York.

[38] Rigg, M., Elias, P., White, M. and Johnson, S (1990) An Overview of the Demand for Graduates. HMSO, London.

[39] Sattinger, M. (1993) "Assignment Models of the Distribution of Earnings". Journal of Economic Literature, 31 (2), pp. 851-880.

[40] Sicherman, N. (1991) "Overeducation' in the Labor Market". Journal of Labor Economics, 9, pp. 101-122.

[41] Sloane, P.J., Battu, H. and Seaman, P.T. (1999) "Overeducation, Undereducation and the British Labour Market". Applied Economics, 31 (11), pp. 1437-1454.

[42] Stiglitz, J. (1997) "Reflections on the Natural Rate Hypothesis". Journal of Economic Perspectives, 11 (1), 3-10.

[43] Thurow, L.C. (1975) Generating Inequality. New York: Basic Books. 
[44] Van Ours, J.C. and Ridder, G. (1995) "Job Matching and Job Competition: Are Lower Educated Workers at the Back of Job Queues?" European Economic Review, 39 (9), pp. 1717-1731.

[45] Welch, F. (1999) "In Defense of Inequality". American Economic Review, Papers and Proceedings, May, pp.1-17.

[46] Wolff, E. (2000) "Technology and the Demand for Skills". In L. Borghans and A. de Grip (eds) The Overeducated worker? The Economics of Skill Utilization, Cheltenham: Edward Elgar.

[47] Wood, A. (1994) North-South Trade, Employment and Inequality, Changing Fortunes in a Skill-Driven World. Oxford: Clarendon Press 